\title{
Effects of the Application of WebQuest to Technology Education on Business Management Students' Critical Thinking Psychology and Operation Capability
}

\author{
Chenin Chen \\ International College, Krirk University, Bangkok, Thailand \\ ORCID: 0000-0002-1404-4587
}

Received: 29 Jul 2020

Accepted: 27 Oct 2020

\begin{abstract}
Along with the rapid development of technology, the constant innovation and application of computer and information technology has information technology change humans' future lifestyles as well as induce comprehensive changes in humans' learning. Due to knowledge digitization, knowledge creation and update is fast that the acceleration and enhancement of learning effectiveness becomes the important issue concerned in global education development. Along with the population of digitization, information technology largely changes life and learning model.

Applying experimental design model to the quasi-experimental research, total 188 business management students of universities in Fujian are preceded technology education with WebQuest. The experimental teaching is preceded 3 hours per week for 16 weeks (total 48 hours). Research results reveal 1. WebQuest would affect critical thinking psychology, 2. WebQuest would affect operation capability, 3. critical thinking psychology presents significantly positive effects on problem clarification in operation capability, 4. critical thinking psychology shows remarkably positive effects on effective interaction in operation capability, and 5. critical thinking psychology reveals notably positive effects on inductive inference in operation capability. According to the results, suggestions are proposed, expecting to help domestic technology education get into organizational and systematic development to further cultivate students' technology literacy.
\end{abstract}

Keywords: WebQuest, technology education, business management students, critical thinking psychology, operation capability

\section{INTRODUCTION}

The boom of information and communication technology has humans rapidly enter the information society and becomes an important indicator to enhance national competitiveness. The rapid emergence and population of information leads humans to the knowledge economic era. Under the international trend of knowledge economic era, the rapid acquisition of knowledge is a key in enhancing competitiveness of nations to largely change humans' learning styles. The rapid knowledge creation and update, due to knowledge digitization, has the acceleration and enhancement of learning effectiveness become a primary issue in global education development. Along with the population of digitization, information technology largely changes life and learning models. The rapid development of technology and the constant innovation and application of computer and information technology result in information technology changing humans' future lifestyles and inducing comprehensive changes in human learning. The promotion of information technology education policy allows education presenting a new learning appearance. Along with the constant 
innovation, research and development, and application of information technology, the convenience of elearning and the diversity of instructional media result in inadequate policy promotion model being eliminated as well as new technology today becoming the history of tomorrow. The discussion of teachers' information technology acceptance therefore becomes important. Finding out the key factors in teachers' information technology acceptance could ensure information technology policy matching the needs of time trend.

Intrinsic technology education model is instructor centered, in which students, with passive learning, listen to teachers' ideas and do not have personal critical discourse of current technology issues. When facing problems, they involuntarily follow the ideas of teachers or the elderly. When encountering sudden situations or problems independently, they realize the lack of self-thinking ability and become panic. Nevertheless, learning without thought is labor lost; it is more important to train a child who would think than a machine which could pass tests. Since WebQuest is proposed, the teaching principle is broadly promoted. WebQuest teaching encourages students' active learning and personal knowledge construction, matches the points of modern learning, stresses on learners enhancing critical thinking and high-level cognitive learning through computer learning, and reinforces students' reflective and critical thinking ability. WebQuest therefore is a powerful tool to induce students' critical thinking. WebQuest is applied in this study to discuss the effect of technology education on business management students' critical thinking psychology and operation capability. It is expected to help domestic technology education get into organizational and systematic development to further cultivate students' technology literacy.

\section{LITERATURE REVIEW}

Fan et al. (2018) pointed out information technology education policy as the compound of information education and education policy that information education policy referred to all information education measures drafted or adopted for information education promotion programs aiming to solve or satisfy students' information acquisition, application, and analysis capability as well as attitudes toward policy information learning. Strawhacker et al. (2018) regarded technology education as the new industrial arts education with technology research as the content, aiming to cultivate national technology literacy so as to present general technology knowledge, understand real meanings, contents, and essence of technology, as well as realize the positive value of technology development in human civilization and social changes and the possible negative effects and impacts. García-Peñalvo and Mendes (2018) proposed to establish correct cognition, concept, and attitude to adapt to current and future technology development, fully apply the positive value of technology through general participation and smart selection, and collaboratively create productive and harmonious technology civilization and human culture. Kurz et al. (2018) regarded technology education as individual innate potential of reasoning and problem solving, imagination, and creation, as well as construction and expression with tools and materials (the beginning of technology and industry) that technology education stressed on developing curriculum content and experiences for human growth and development based on such rich potentials.

Jung and Won (2018) pointed out WebQuest as project-oriented learning, simulating problems and tasks in authentic situations, allowing learners thinking and searching data on the Internet, and placing learners in exploratory problems to induce learners' learning motivation and allow learners debating, arguing, discussing, doubting, and proving problems, understanding knowledge, comprehending knowledge, consolidating knowledge, and utilizing knowledge from various points of view. Eldor (2017) mentioned that WebQuest emphasized learners' motivation, encouraged team cooperative learning, and allowed learners reflecting learning, according to scaling scale, to correct the work step by step. Teig et al. (2018) considered that WebQuest teaching design aimed to have learners actively participate in tasks and request learners, aiming at tasks, to complete one or a series of works, products, or performance for the practical evaluation of teachers and peers, as well as emphasized learners' self-evaluation and mutual evaluation. In this case, WebQuest was high-level thinking learning for learners. Bani-Melhem et al. (2018) mentioned that real WebQuest was the scaffolding learning structure to connect useful resources and real tasks on the Internet to induce students' research motivation of open-ended questions, development of individual professional 
knowledge, and transformation of newly acquired information into higher level comprehension. Yang et al. (2019) regarded WebQuest as learner-centered learning; when encountering problems, the team collaboratively discussed and defined problems; after the division of labor, learners engaged in the cognition of problem solving to organize concepts and principles in learning activities and eventually acquire problem solutions and the related cognitive comprehension through sharing and inference. Learners could actively and collaboratively construct knowledge with peers and cultivate the critical thinking ability. The following hypothesis is therefore proposed in this study.

\section{H1: WebQuest would affect critical thinking psychology.}

Su et al. (2018) indicated that teachers were simply the coadjutants in WebQuest to provide necessary guides and prompts, without giving lectures or directly delivering knowledge. It aimed that learners could gradually accumulate rich knowledge in the self-search and problem-solving process; and, the main characters on the learning stage were undertaken by learners through team discussion. Chalmers (2018) considered that students, after WebQuest, should learn to analyze deep knowledge of a subject as well as transform and transfer knowledge. As a result, the knowledge and capability, which students could grasp in the WebQuest process, at least contained data analysis, criticism and evaluation, interpersonal cooperation and coordination, self-management, and content integration and innovation. Tran (2019) pointed out the value of WebQuest as students not spending time on aimless search but immediately connecting Internet resources for reading and evaluation to exclude the possibility of students searching improper or incorrect contents. By grouping students for courses to reduce the use of computers, such arrangement prepared the environment for students' cooperative learning, allowed students successfully collecting information, and increased the participation of those with low learning motivation or learning disability. Bers (2018) also pointed out several advantages of using WebQuest as teaching tool, including reducing the coverage of web exploration and guiding search directions for students. Such a measure was a challenge for students' intelligence and academic operation capability, rather than simply the excellence of search skills, and provided students with safe network environment; and, the curriculum allowed students presenting multiple opinions of affairs. Gomes et al. (2018) regarded WebQuest as the tool with structure, organization, and time efficiency, which could be used, by educators, for providing students with large amount and useful network information as well as inducing learners' critical thinking ability. Hull (2018) explained the basic principle of WebQuest as helping students, providing resources for them, offering cognitive support with knowledge scaffolding, and training students' operation capability of independent research and problem solving. Accordingly, the following hypothesis is proposed in this study.

\section{H2: WebQuest would affect operation capability.}

Park and Jo (2018) referred the psychological tendency of critical thinking to critical thinking attitude, commitment, and intention. The psychological tendency of critical thinking would induce individual motivation of critical thinking to induce individual operation capability of critical thinking. Heikkilä and Mannila (2018) mentioned that an individual with the attitudes to make clear statement, search sufficient reasons for reasoning information, apply resources with higher reliability, be thoughtful, present empathy, consider others' points of view and emotion, keep principles and basic concerns in mind, be open-minded, overcome typical self-centered intention, and search multiple reasoning methods presented strong critical thinking tendency. Cairns and Areepattamannil (2017) pointed out ability, skill, or knowledge as the important bases of critical thinking; a person without critical thinking tendency could hardly transform critical thinking into behavioral performance, i.e. not being able to insist on doing what ought to be done. Ones with critical thinking skills but not willingness to practice could not become good critical thinkers nor enhance the operation capability of critical thinking. Consequently, the following hypotheses are proposed in this study.

H3: Critical thinking psychology shows significantly positive effects on problem clarification in operation capability.

H4: Critical thinking psychology reveals remarkably positive effects on effective interaction in operation capability. 
H5: Critical thinking psychology appears notably positive effects on inductive inference in operation capability.

\section{RESEARCH METHOD}

\section{Measurement of Research Variable}

\section{Critical thinking psychology}

Referring to Lin et al. (2019), critical thinking psychology is divided into three dimensions in this study.

1. Going into the whys and wherefores of something: Critical thinkers are diligent in searching relevant information, willing to rethinking solutions, and perseverant to search results.

2. Self-reflection: Critical thinkers would attempt to use the rich information sources for assessment, reflect judgment, judge standards based on reasons and careful attitude, and keep cautious attitude in complicate situations.

3. Being confident: With proofs, critical thinkers would believe in the reasoning, are confident of facing public questioning, and could timely stabilize the position with sufficient evidence or reasons.

\section{Operation capability}

Referring to Chen et al. (2019), the followings are proposed.

1. Problem clarification: The specific behavior is to definitely grasp the core or point of problems or issues, i.e. being able to definitely point out the meanings or central idea and make questions for clarification, when facing affairs or information.

2. Effective interaction: Critical thinking ability contains strategies to interact with others, including proper timing to take actions, discussing with others, and expressing personal opinions.

3. Inductive inference: Critical thinking involves in various cognition and metacognition skills, e.g. analysis, interpretation, reasoning, explanation, evaluation, creative application of information, making conclusion, interacting with others, and self-regulation; such skills or abilities could be classified into three basic abilities of clarification, establishment of complete inference basis, and reasoning.

\section{Research Subject and Sampling Data}

Experimental design model is applied to the quasi-experimental research on total 188 business management students of universities in Fujian. WebQuest is used for the 16-week technology education (3 hours per week for total 48 hours). The collected questionnaire are analyzed with SPSS, and factor analysis, reliability analysis, regression analysis, and analysis of variance are applied to test various hypotheses.

\section{Analysis Method}

Analysis of variance is utilized for discussing the difference of WebQuest in critical thinking psychology and operation capability, and regression analysis is applied to understand the relations between critical thinking psychology and operation capability.

\section{ANALYSIS RESULT}

\section{Reliability and Validity Analysis}

In this study, critical thinking psychology and operation capability, with factor analysis, are separately extracted three factors. 
Table 1. Factor analysis

\begin{tabular}{lcccc}
\hline variable & factor & eigenvalue & $\alpha$ & $\begin{array}{c}\text { cumulative variance } \\
\text { explained }\end{array}$ \\
\hline critical thinking & $\begin{array}{c}\text { going into the whys and } \\
\text { psychology }\end{array}$ & 1.838 & 0.87 & 73.622 \\
& $\begin{array}{c}\text { self-reflection } \\
\text { being confident }\end{array}$ & 2.045 & 0.81 & 0.84 \\
\hline operation & problem clarification & 2.591 & 0.85 & 75.416 \\
capability & effective interaction & 3.417 & 0.86 & 0.88 \\
& inductive inference & 2.533 & & \\
\hline
\end{tabular}

Table 2. Variance analysis of WebQuest on critical thinking psychology

\begin{tabular}{lcccc}
\hline variable & & $\mathrm{F}$ & $\mathrm{P}$ & Scheffe post hoc \\
\hline WebQuest & $\begin{array}{c}\text { going into the whys and } \\
\text { wherefores of something }\end{array}$ & 11.752 & $0.000^{* *}$ & WebQuest>general traditional learning \\
& $\begin{array}{c}\text { self-reflection } \\
\text { being confident }\end{array}$ & 16.433 & $0.000^{* *}$ & WebQuest>general traditional learning \\
& 14.218 & $0.000^{* *}$ & WebQuest>general traditional learning \\
\hline
\end{tabular}

Note: ${ }^{*}$ stands for $\mathrm{p}<0.05, * *$ for $\mathrm{p}<0.01$

Table 3. Variance analysis of WebQuest on operation capability

\begin{tabular}{llccc}
\hline variable & & $\mathrm{F}$ & $\mathrm{P}$ & Scheffe post hoc \\
\hline WebQuest & problem clarification & 18.617 & $0.000^{* *}$ & WebQuest>general traditional learning \\
& effective interaction & 21.452 & $0.000^{* *}$ & WebQuest>general traditional learning \\
& inductive inference & 24.916 & $0.000^{* *}$ & WebQuest>general traditional learning \\
\hline
\end{tabular}

Note: ${ }^{*}$ stands for $p<0.05,{ }^{* *}$ for $p<0.01$

\section{Effects of Learning Style on Critical Thinking Psychology and Operation Capability}

\section{Variance analysis of learning style on critical thinking psychology}

According to analysis of variance, the difference of learning style in critical thinking psychology is discussed, i.e. analyses and explanations of WebQuest and general traditional learning. Regarding the difference of learning style in critical thinking psychology, Table 2, WebQuest presents higher going into the whys and wherefores of something than general traditional learning. In terms of difference of learning style in selfreflection, WebQuest shows significantly higher self-reflection than general traditional learning. In regard to the difference of learning style in being confident, WebQuest appears higher being confident than general traditional learning. $\mathrm{H} 1$ is therefore supported.

\section{Variance analysis of learning style on operation capability}

According to analysis of variance, the difference of learning style in operation capability is discussed, i.e. analyses and explanation of WebQuest and general traditional learning. In terms of learning style in operation capability, WebQuest reveals higher problem clarification than general traditional learning. Regarding learning style in effective interaction, WebQuest presents higher effective interaction than general traditional learning. In regard to learning style in inductive inference, WebQuest shows remarkably higher inductive inference than general traditional learning. As a result, $\mathrm{H} 2$ is supported.

\section{Correlation Analysis of Critical Thinking Psychology and Operation Capability}

\section{Correlation analysis of critical thinking psychology and problem clarification}

To test $\mathrm{H} 3$, the analysis results, Table 4 , reveal notable effects of going into the whys and wherefores of something $\left(\beta=2.043^{* *}\right)$, self-reflection, $\left(\beta=2.122^{* *}\right)$, and being confident $\left(\beta=2.235^{* *}\right)$ on problem clarification that $\mathrm{H} 3$ is supported. 
Table 4. Analysis of critical thinking psychology to operation capability

\begin{tabular}{|c|c|c|c|c|c|c|}
\hline \multirow{3}{*}{$\begin{array}{l}\text { dependent variable } \rightarrow \\
\text { independent variable } \downarrow \\
\text { critical thinking psychology }\end{array}$} & \multicolumn{6}{|c|}{ operation capability } \\
\hline & \multicolumn{2}{|c|}{ problem clarification } & \multicolumn{2}{|c|}{ effective interaction } & \multicolumn{2}{|c|}{ inductive inference } \\
\hline & $\beta$ & $\mathrm{P}$ & $\beta$ & $\mathrm{P}$ & $\beta$ & $\mathrm{P}$ \\
\hline $\begin{array}{l}\text { going into the whys and } \\
\text { wherefores of something }\end{array}$ & $2.043 * *$ & 0.000 & $2.412 * *$ & 0.000 & $2.281^{* *}$ & 0.000 \\
\hline self-reflection & $2.122 * *$ & 0.000 & $2.388 * *$ & 0.000 & $2.342 * *$ & 0.000 \\
\hline being confident & $2.235^{* *}$ & 0.000 & $2.575^{* *}$ & 0.000 & $2.195 * *$ & 0.000 \\
\hline $\mathrm{F}$ & \multicolumn{2}{|c|}{21.375} & \multicolumn{2}{|c|}{27.583} & \multicolumn{2}{|c|}{34.291} \\
\hline significance & \multicolumn{2}{|c|}{$0.000 * * *$} & \multicolumn{2}{|c|}{$0.000 * * *$} & \multicolumn{2}{|c|}{$0.000 * * *$} \\
\hline $\mathrm{R} 2$ & \multicolumn{2}{|c|}{0.206} & \multicolumn{2}{|c|}{0.267} & \multicolumn{2}{|c|}{0.335} \\
\hline adjusted R2 & \multicolumn{2}{|c|}{0.192} & \multicolumn{2}{|c|}{0.248} & \multicolumn{2}{|c|}{0.312} \\
\hline
\end{tabular}

Note: ${ }^{*}$ stands for $\mathrm{p}<0.05,{ }^{* *}$ for $\mathrm{p}<0.01$

Data source: Self-organized in this study

\section{Correlation analysis of critical thinking psychology and effective interaction}

To test $\mathrm{H} 4$, the analysis results, Table 4 , appear significant effects of going into the whys and wherefores of something $\left(\beta=2.412^{* *}\right)$, self-reflection $\left(\beta=2.388^{* *}\right)$, and being confident $\left(\beta=2.575^{* *}\right)$ on effective interaction that $\mathrm{H} 4$ is supported.

\section{Correlation analysis of critical thinking psychology and inductive inference}

To test $\mathrm{H} 5$, the analysis results, Table 4 , reveal remarkable effects of going into the whys and wherefores of something $\left(\beta=2.281^{* *}\right)$, self-reflection $\left(\beta=2.342^{* *}\right)$, and being confident $\left(\beta=2.195^{* *}\right)$ on inductive inference that $\mathrm{H} 5$ is supported.

\section{CONCLUSION}

The research findings show that integrating technology education into WebQuest teaching allows business management students actively constructing personal knowledge and cultivating the critical thinking tendency and ability. The results prove that business management students, under the WebQuest teaching structure, present high learning motivation and enhance the critical thinking psychology and operation capability. Such a result appears learning transfer to have business management students become curious, be willing to think, and be willing to express ideas to interact with others. Through questioning and observation, business management students reflect themselves, learn others' advantages, and enhance the critical thinking ability. Business management students used to consider of making mistakes by having different measures from teachers; however, they now would think of many right measures, simply with different steps. Moreover, business management students would use division of labor to have the team presentation be distinct. Some members would search reference websites, while others would search other websites. It allows business management students being used to expressing personal ideas and questioning problems in the presentation so that business management students would present active learning, and the constructed knowledge and acquired ability would lead them to deep learning.

\section{SUGGESTION}

Aiming at above research results, the following suggestions are proposed in this study.

1. Business management students' critical thinking ability is not naturally generated by time, but led by parents or teachers. In traditional teaching, teachers rushed to indoctrinate knowledge to students and students were used to accept external information, but not actively participating in learning or constructing personal knowledge. For the first presentation, offstage students quietly wait for teachers' criticism and suggestions. For the second presentation, business management students, under the force of teachers, have to give onstage students praise and suggestions. Students are then gradually brave to 
express personal opinions; it is discovered that business management students' opinions are beyond imagination. Business management students' potential is so huge that teachers should not be complacent, but should innovate the teaching and advance students' ability.

2. Business management students' individual differences would affect the effectiveness of critical thinking teaching model. Instructors should provide learning assistance for different types of students. In regard to the promotion of presentation and discussion, instructors could have students with better performance hold the demonstration for business management students' imitation and learning. Regarding the participation in business management students' speech, teachers could include the discussion process into the term performance and timely give oral support to create good discussion situation. For shy and silent business management students, instructors should actively understand the reason and guide them to realize the importance of critical thinking to the future life.

3. Reference websites for business management students searching data in WebQuest should be plenty and the content should satisfy students' needs; otherwise, business management students would simply search on the search engine. The selection of reference websites therefore should match business management students' reading ability. It might not be easy, as it is rather impossible for private webpages making the version suitable for different age groups. The sole expectation is that the webpages of governmental departments could satisfy the needs for online reading.

\section{ACKNOWLEDGEMENTS}

The author appreciates financial support from Ming Zhong International Education (Thailand) Co., Ltd. for the research, and publication of this article.

\section{REFERENCES}

Bani-Melhem, S., Zeffane, R., \& Albaity, M. (2018). Determinants of employees' innovative behavior. International Journal of Contemporary Hospitality Management, 30(3), 1601-1620. https://doi.org/10.1108/IJCHM-02-2017-0079

Bers, M. U. (2018). Coding and computational thinking in early childhood: The impact of ScratchJr in Europe. European Journal of STEM Education, 3(3), 1-13. https://doi.org/10.20897/ejsteme/3868

Cairns, D., \& Areepattamannil, S. (2017). Exploring the relations of inquiry-based teaching to science achievement and dispositions in 54 countries. Research in Science Education, 1-23. https://doi.org/10.1007/s11165-017-9639-x

Chalmers, C. (2018). Robotics and computational thinking in primary school. International Journal of ChildComputer Interaction, 17, 93-100. https://doi.org/10.1016/j.ijcci.2018.06.005

Chen, Y. C., Lu, Y. L., \& Lien, C. J. (2019). Learning environments with different levels of technological engagement: A comparison of game-based, video-based, and traditional instruction on students' learning. Interactive Learning Environments, 1-17.

Eldor, L. (2017). The relationship between perceptions of learning climate and employee innovative behavior and proficiency. Personnel Review, 46(8), 1454-1474. https://doi.org/10.1108/PR-08-2016-0202

Fan, J. L., Ke, R. Y., Yu, S., \& Wei, Y. M. (2018). How does coal-electricity price linkage impact on the profit of enterprises in China? Evidence from a Stackelberg game model. Resources, Conservation and Recycling, 129, 383-391. https://doi.org/10.1016/j.resconrec.2016.09.016

García-Peñalvo, F. J., \& Mendes, A. J. (2018). Exploring the computational thinking effects in pre-university education. Computers in Human Behavior, 80, 407-411. https://doi.org/10.1016/j.chb.2017.12.005 
Gomes, T., Falcão, T., \& Tedesco, P. (2018). Exploring an approach based on digital games for teaching programming concepts to young children. International Journal of Child-Computer Interaction, 16, 7784. https://doi.org/10.1016/j.ijcci.2017.12.005

Heikkilä, M., \& Mannila, L. (2018). Debugging in Programming as a multimodal practice in early childhood education settings. Multimodal Technologies Interact, 2(3), 42. https://doi.org/10.3390/mti2030042

Hull, D. M. (2018). Teacher-Led Math Inquiry: A Cluster Randomized Trial in Belize. Educational Evaluation and Policy Analysis, 40(3), 336-358. https://doi.org/10.3102/0162373718768430

Jung, S., \& Won, E. (2018). Systematic review of research trends in robotics education for young children. Sustainability, 10(4), 905. https://doi.org/10.3390/su10040905

Kurz, V., Hüsig, S., \& Dowling, M. (2018). What drives different employee types of innovative behaviour? Development and test of an integrative model of employee driven innovation in German firms. International Journal of Entrepreneurship and Innovation Management, 22(4/5), 397. https://doi.org/10.1504/IJEIM.2018.092955

Lin, Y. L., Huang, S. W., \& Chang, C. C. (2019). The impacts of a marine science board game on motivation, interest, and achievement in marine science learning. Journal of Baltic Science Education, 18(6), 907923. https://doi.org/10.33225/jbse/19.18.907

Park, S., \& Jo, S. J. (2018). The impact of proactivity, leader-member exchange, and climate for innovation on innovative behavior in the Korean government sector. Leadership \& Organization Development Journal, 39(1), 130-149. https://doi.org/10.1108/LODJ-09-2016-0216

Strawhacker, A. L., Lee, M.S.C., \& Bers, M. U. (2018). Teaching tools, teacher's rules: Exploring the impact of teaching styles on young children's programming knowledge in ScratchJr. The International Journal of Technology and Design Education, 28(2), 347-376. https://doi.org/10.1007/s10798-017-9400-9

Su, J., Xu, H., Xin, N., Cao, G., \& Zhou, X. (2018). Resource Allocation in Wireless Powered loT System: A Mean Field Stackelberg Game-Based Approach. Sensors, 18(10), 3173. https://doi.org/10.3390/s18103173

Teig N., Scherer R., \& Nilsen, T. (2018). More isn't always better: The curvilinear relationship between inquirybased teaching and student achievement in science. Learning and Instruction, 56, 20-29. https://doi.org/10.1016/j.learninstruc.2018.02.006

Tran, Y. (2019). Computational Thinking Equity in Elementary Classrooms: What Third-Grade Students Know and Can Do. Journal of Educational Computing Research, 57(1), 3-31. https://doi.org/10.1177/0735633117743918

Yang, X., Cheng, P. Y., Lin, L., Huang, Y. M., \& Ren, Y. (2019). Can an Integrated System of Electroencephalography and Virtual Reality Further the Understanding of Relationships Between Attention, Meditation, Flow State, and Creativity? Journal of Educational Computing Research, 57(4), 846-876. https://doi.org/10.1177/0735633118770800

Correspondence: Chenin Chen, International College, Krirk University, Bangkok, Thailand. E-mail: chenin@email.kirk.ac.th 